v.23, n.1, Especial do IV Simpósio de Nutrição de Animais de Companhia, p.13-14, 2018

\title{
ESTUDO DAS NECESSIDADES NUTRICIONAIS DE CÃES MACHOS REPRODUTORES
}

(Study of the nutritional needs of male breeding dogs)

\author{
Priscila Vecchietti ${ }^{1}$, Lucélia Hauptli ${ }^{1}$, Priscila O. Moraes ${ }^{1}$, Keisy A. S. Amorim ${ }^{1}$, Bruna C.S. Appelt ${ }^{1}$
}

1Universidade Federal de Santa Catarina, Florianópolis - SC.

Email: priscilavecchietti@hotmail.com

Resumo: $O$ objetivo do trabalho foi definir as necessidades nutricionais de cães machos reprodutores através de publicações científicas e, a partir destas, verificar alimentos completos e suplementos comerciais que atendam essa categoria. Foram identificadas oito publicações com 124 cães avaliados. Os nutrientes avaliados foram: Vitamina E, Selênio, Ômega 3 e Ômega 6. Os parâmetros usuais na avaliação de qualidade de sêmen foram: volume, motilidade, vigor espermático e concentração espermática. $O$ estudo mostrou que 0 ideal para cães machos reprodutores será seguir as tabelas oficiais de exigências nutricionais, uma dieta com: $3.750 \mathrm{kcal} / \mathrm{kg}$; proteína bruta de 24\%; Cálcio de 1,113\%; Fósforo de 0,905\%; Selênio de 0,408\%; Vitamina E de 40 mg/kg e Ômegas 3 e 6 de 5500 e 300 mg, respectivamente. Para suplementação, além das exigências nutricionais, recomenda-se: Vitamina E: $50 \mathrm{mg} / \mathrm{kg}$; Selênio: 0,60 mg/kg; Ômega 3: 7,2 mg/kg; Ômega 6: $25 \mathrm{mg} / \mathrm{kg}$ de peso corporal durante média de 60 dias. Foram encontrados cinco alimentos completos comerciais que atendem as necessidades. Os alimentos necessitam de suplementação. Foram identificados três suplementos que atenderam, as recomendações estimadas.

Palavras-chave: micronutrientes; pets; qualidade de sêmen

Abstract: The objective of this work was to define the nutritional needs of male breeding dogs through scientific publications and to verify complete foods and commercial supplements that meet these dogs. Eight publications with 124 dogs were found. The nutrients evaluated were: Vitamin E, Selenium, omega 3 and omega 6 fatty acids. The usual parameters in the evaluation of semen quality were: volume, motility, sperm vigor and sperm concentration. The study showed that the ideal for male breeding dogs will to use the official Nutrient Requirement Tables: $3,750 \mathrm{kcal}$ / kg; 24\% crude protein; 1.113\% Calcium; 0.905\% Phosphorus; 0.408\% Selenium; 40 $\mathrm{mg} / \mathrm{kg}$ Vitamin $\mathrm{E}$; and Omega 3 and 6 of 5500 and $300 \mathrm{mg}$, respectively. For supplementation, in addition to nutritional requirements, it is recommended: Vitamin E: 50 mg / kg; Selenium: 0.60 mg / kg; Omega 3: 7.2 mg / kg; Omega 6: 25 mg / kg body weight for a mean of 60 days. Five complete commercial foods were found that meet the needs. Food needs supplementation. Three supplements were identified that met the estimated recommendations.

Key words: micronutrients; pets; semen quality

Introdução: O mercado "pet food" apresenta alimentos completos para cadelas reprodutoras, onde é possível adquirir alimentos específicos para gestantes e lactantes, porém não há esta especificidade para machos reprodutores no Brasil e poucas ofertas em nível mundial. O National Research Council (NRC, 2006) considera um cão macho reprodutor na mesma categoria de exigência de um cão em crescimento. 
Logo, o objetivo deste trabalho foi definir as necessidades nutricionais de cães machos reprodutores através de publicações científicas sobre os nutrientes e energia e, a partir destas, verificar a existência de alimentos completos e suplementos disponíveis comercialmente que atendam a categoria.

Material e Métodos: Foi realizada uma revisão sistemática de literatura científica de necessidades nutricionais de cães machos reprodutores. Foram identificadas oito publicações, com 124 cães avaliados, com média de peso 20,75 kg ( \pm 10$)$ e com idade média de 3,9 anos $( \pm 2,38)$. Os principais nutrientes abordados foram: Vitamina E, Selênio, Ômega 3 e Ômega 6. Os parâmetros de qualidade de sêmen avaliados foram: volume, motilidade espermática, vigor espermático e concentração espermática. Os resultados significativos dos nutrientes em relação a cada variável de qualidade espermática foram avaliados por equações de regressão. Todos os resultados tratam de suplementação média de 60 dias para o cão macho reprodutor. A partir das informações de recomendação dos nutrientes para otimização dos parâmetros avaliados, foi realizada uma busca de alimentos completos e suplementos para cães, disponíveis no mercado petfood.

Resultados e Discussão: As melhorias da qualidade de sêmen ocorreram quando as exigências nutricionais seguiram o NRC (NRC, 2006) e foram suplementados os nutrientes nas recomendações: vitamina $E$ de $50 \mathrm{mg} / \mathrm{kg}$, Selênio de 0,60 mg/kg, Ômega 3 de 7,2 mg/kg e Ômega 6 de $25 \mathrm{mg} / \mathrm{kg}$ de peso corporal durante média de 60 dias. A Vitamina $E$ o Selênio agem como antioxidantes que mantêm a integridade da membrana espermática e suas propriedades fisiológicas são necessárias para o sucesso da fertilização (PUTAROV, 2010). Foram encontrados cinco alimentos completos comerciais que atendem as necessidades preconizadas para cães machos reprodutores com média de $20 \mathrm{~kg}$ de peso corporal. E três suplementos que atenderam as recomendações estimadas. Logo, é possível oferecer um manejo nutricional adequado a cães machos na fase de reprodução, com o objetivo de alcançar um máximo desempenho reprodutivo na qualidade do sêmen.

Conclusão: Para cães machos reprodutores, além das exigências nutricionais padrões, recomenda-se suplementação de Vitamina E: $50 \mathrm{mg} / \mathrm{kg}$; Selênio: 0,60 mg/kg; Ômega 3: 7,2 mg/kg; Ômega 6: $25 \mathrm{mg} / \mathrm{kg}$ de peso corporal durante média de 60 dias. Existem no mercado brasileiro alimentos completos e suplementos que podem atender estas exigências e suplementações recomendadas.

Referências: NATIONAL RESEARCH COUNCIL - NRC. Nutrient Requirements of Dogs and Cats. Washington, DC: National Academy Press, 2006. 424p. ISBN: 9780-309-08628-8.

PUTAROV, T.C. Avaliação de fontes de selênio e seus efeitos no perfil metabólico e condição reprodutiva de cães. Botucatu: Universidade Estadual Paulista, 72p. Dissertação (Mestrado em Zootecnia). UNESP, 2010. 